\title{
Journal Of Vocational Education And Teehnology
}

Volume 1, No 1, April 2020

Online: http://ojs.upy.ac.id/ojs/index.php/jatve

\section{FENOMENA ALIRAN UDARA-AIR BERLAWANAN ARAH PADA} PIPA HORIZONTAL PADA L/D = 25 DAN L/D = 50

\author{
YuliaVenti Yoanita ${ }^{1}$, Sinung Tirtha $P^{2}$, Eli Kumolosari ${ }^{3}$, Bayu Gilang Purnomo ${ }^{4}$. \\ ${ }^{1}$ Fakultas Keguruan dan Ilmu Pendidikan, Universitas PGRI Yogyakarta, Indonesia. \\ Email: yventiyoanita@upy.ac.id \\ ${ }^{2}$ Lembaga Penerbangan dan Antariksa Nasional (LAPAN), Indonesia. \\ ${ }^{3}$ Sekolah Tinggi Teknologi Adisutjipto, Indonesia. \\ ${ }^{4}$ Fakultas Keguruan dan Ilmu Pendidikan, Universitas PGRI Yogyakarta, Indonesia.
}

\begin{abstract}
ABSTRAK
Fenomena aliran sangat penting dalam rangka untuk mengetahui lebih lanjut tentang mekanisme Counter-Current Flow Limitation (CCFL) atau transisi dari aliran berlawanan arah menjadi aliran searah. Pola aliran stratified menjadi karakter yang awal dalam fenomena selanjutnya. Peningkatan kecepatan udara yang kecil akan sangat mempengaruhi pola aliran berubah. Gangguan antar muka akan selalu besar seiring dengan peningkatan kecepatan udara. Alat yang digunakan untuk penelitian ini sama dengan salah satu komponen pada Pressurized Water Reactor (PWR) yang disebut hot leg dengan perbandingan 1/30. Hot leg adalah bagian pipa yang diamati dalam penelitian ini. Dimensi dari hotleg berupa pipa mendatar, pipa miring dan belokan yang terpasang menjadi satu dalam suatu saluran pokok PWR. Pada penelitian ini simulator hot leg dibuat dengan $\mathrm{L} / \mathrm{D}=50$ dan $\mathrm{L} / \mathrm{D}=25$. Simulator ini terdiri dari pipa horizontal, belokan dan miring dengan sudut kemiringan 50o. Visual yang dapat diamati dalam saluran hotleg, sehingga fenomena-fenomena yang terjadi dapat diamati secara rinci. Pengamatan visual dilakukan dengan menggunakan kamera berkecepatan tinggi. Sehingga data yang didapat dan diolah didapatkan secara valid. Hasil pengamatan yang diperoleh adalah pola aliran yang terjadi pada pipa horizontal. Penambahan kecepatan udara menyebabkan cepat terjadinya perubahan pola aliran pada $\mathrm{L} / \mathrm{D}=50$. Sedangkan, pada $\mathrm{L} / \mathrm{D}=25$ perubahan pola aliran dapat terjadi dengan kecepatan udara yang besar.
\end{abstract}

Kata kunci: flooding, hot leg, Pressurized Water Reactor, hydraulic jump.

\section{ABSTRACT}

The flow phenomenon is very important in order to find out further information about the mechanism of Counter-Current Flow Limitation (CCFL) or the transition from counter-flow to direct flow. Stratified flow patterns is the initial character for the next phenomenon. A small increase in air velocity is greatly affect the changing of flow pattern. Interface disruption will be greater along with the increase in air velocity. This study used the same device as one of the components in a Pressurized Water Reactor (PWR) called a hot leg with a ratio of $1 / 30$. Hot leg was the part of the pipe observed in this study. The dimensions of the hot leg were horizontal pipes, oblique pipes and bend pipe, which were installed together in a PWR main channel. In this study, the hot leg simulator was made with $\mathrm{L} / \mathrm{D}=50$ and $\mathrm{L} / \mathrm{D}=25$. This simulator consisted of horizontal, bend and oblique pipes with a tilt angle of 50O. Visual can be observed in hotleg channels, so that the phenomena occured can be observed in detail. Visual observations were conducted using a high-speed camera, so that the data obtained and processed was valid. The observations obtained were flow patterns that occurred in horizontal pipes. The increase in air velocity caused faster changes in flow patterns at $\mathrm{L} / \mathrm{D}=50$. Meanwhile, at $\mathrm{L} / \mathrm{D}=25$ changes in flow patterns occurred in high velocity of air.

Keywords: flooding, hot leg, Pressurized Water Reactor, hydraulic jump. 


\section{PENDAHULUAN}

Aliran gas-cair adalah aliran fluida dua macam zat yang berbeda fase mengalir secara bersamaan dalam suatu saluran. Aliran dua fase cair dan gas, aliran dua fase cair dan padat atau aliran dua fase gas dan padat. Aliran dua fase ini banyak ditemukan pada berbagai instalasi mesin, seperti instalasi pompa air lumpur yang mengalirkan zat cair dan padat, instalasi pendingin yang mengalirkan fluida freon dalam fase gas-cair atau instalasi pada aplikasi reaktor nuklir.

Pada aliran satu fase, pressure drop dipengaruhi oleh Reynolds number yang merupakan fungsi dari viskositas, berat jenis fluida dan diameter pipa. Sedangkan aliran dua fase dipengaruhi oleh Reynolds number, interaksi antar fase, tegangan permukaan, pergerakan fluida dan hambatan-hambatan yang ada di dalam pipa.

Di sebagian industri aliran dua fase ini tidak diinginkan, karena memiliki karakteristik yang dapat menimbulkan kerugian yaitu perubahan tekanan yang mendadak dan cukup besar. Namun pada aplikasi tertentu hal ini masih diteliti karena fenomena yang ada pada aliran tersebut bias dimanfaatkan. Sebagai contoh pada Pressurized Water Reactor (PWR) di pembangkit listrik tenaga nuklir. Gambar 1. merupakan diagram skema dari PWR. Pada pembangkit listrik ini terdapat tiga sistem pipa yang menyirkulasikan aliran fluida. Sirkuit Primer menyirkulasikan air dari reaktor, Sirkuit Sekunder menyirkulasi uap akibat dari pemanasan saluran primer selanjutnya menggerakkan turbin dan sirkulasi proses pendinginan atau disebut Cooling Tower. Air pada saluran primer dipanaskan di tabung reaktor bertekanan (reactor pressure vessel, RPV) dan mengalir menuju pembangkit uap (steam generator, $\mathrm{SG})$.

Pada PWR, saluran primer akan membawa panas ke saluran Sekunder. Selanjutnya gas bertekanan dimanfaatkan untuk memutar turbin generator listrik. Pipa yang menghubungkan tabung reaktor dan pembangkit uap disebut pipa hot leg. Dalam kasus PWR KONVOI Jerman, pipa hot leg terdiri dari pipa horizontal, sebuah belokan dan sebuah pipa miring seperti ditunjukkan pada Gambar 1. Dalam scenario loss-ofcoolant-accident (LOCA), yang disebabkan oleh kebocoran pada saluran primer, reaktor akan mengalami penurunan tekanan (depressurized) sehingga timbul proses penguapan di saluran primer tersebut. Uap yang dihasilkan akan mengalir ke pembangkit uap (dalam sirkuit primer) melalui pipa hot leg.

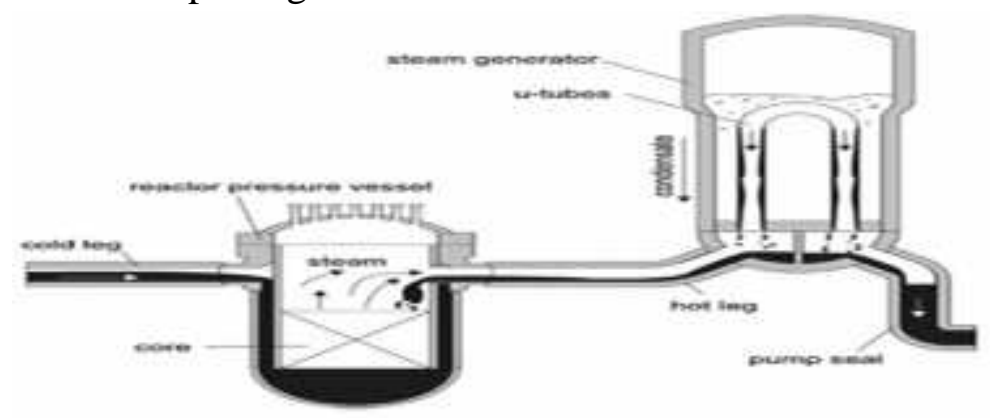

Gambar 1. Konfigurasi pempipaan PWR Konvoi German dan jalur aliran (Seidel dkk.,2010) 
Dalam beberapa skenario, keberhasilan pendinginan inti reactor tersebut tergantung pada perilaku aliran berlawanan arah ini. Aliran berlawanan arah hanya stabil pada jangkauan laju aliran massa dari gas dan cair dalam jumlah tertentu. Jika laju aliran massa gas dinaikkan pada nilai tertentu, sebagian dari kondensat akan menunjukkan pembalikan aliran dan akan tertahan oleh uap dengan arah aliran berlawanan sehingga menuju pembangkit uap (steam generator). Fenomena ini dikenal sebagai Countercurrent Flow Limitation (CCFL) atau awal terjadinya flooding. Pada situasi ini pendinginan inti reaktor tidak terjadi.

Perubahan pola aliran dipengaruhi oleh geometri pipa, kecepatan air dan kecepatan gas. Fenomena flooding selalu diawali dengan ketidakstabilan aliran film diikuti adanya pola aliran seperti droplet, slug serta churn. Saat flooding pola aliran tersebut saling berinteraksi dan membentuk gelombang. Pada aliran gas yang besar permukaan film yang bergerak ke bawah dan gradien tekanan meningkat tajam. Peningkatan kecepatan gas menyebabkan pengangkatan sebagian air dan peningkatan ketebalan film secara mendadak terjadi lebih cepat pada jarak relatif lebih jauh.

Choi dan No., 1995 menjelaskan bahwa mekanisme flooding pada pipa mendekati horisontal dapat dikelompokkan seperti yang ditunjukkan Gambar 2. Mekanisme inner flooding banyak dipengaruhi oleh terbentuknya slug.

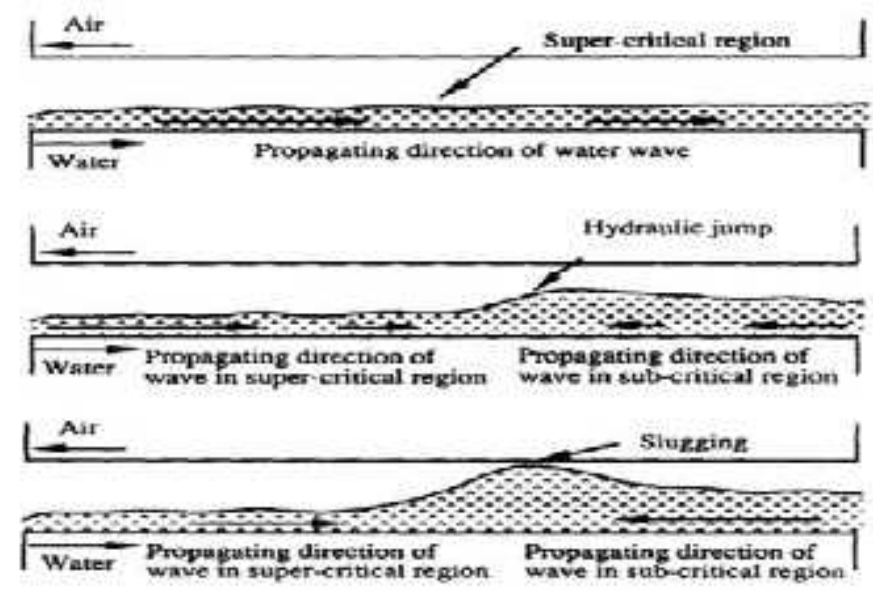

Gambar 2. Mekanisme flooding dengan sudut kemiringan pipa $0,69^{\circ}$ (Choi dan No., 1995).

Flooding adalah peristiwa pembalikan arah aliran fluida cair yang semula berlawanan arah menjadi searah dengan aliran udara, faktor-faktor yang mempengaruhi terjadinya flooding yaitu diameter dan panjang saluran, kekasaran permukaan dinding saluran, dan sistem inlet dan outlet saluran.
Gargalo dkk.(2005) mengemukakan bahwa aliran subkritis merupakan kondisi awal terjadinya flooding. Permulaan flooding bersesuaian dengan transisi dari aliran superkritis menuju aliran subkritis melalui sebuah hydraulic jump.

Barnea dkk. (1986) menyatakan bahwa permulaan flooding disebabkan ketidakstabilan aliran sepanjang pipa. Mouza 
dkk. (2003) menjelaskan bahwa permulaan flooding terjadi karena ketidakstabilan aliran cairan di dalam pipa sehingga terjadi gelombang, yang seiring dengan perjalanannya gelombang ini akan tumbuh. Dengan adanya aliran gas yang berlawanan dengan arah aliran air, dimungkinkan gelombang akan tumbuh dan akan terpecah menjadi droplet kecil. Fenomena sesuai dengan penelitian Deendarlianto dkk. (2004) ketika menggunakan pipa miring.

Wongwises (1996) menggambarkan sebuah kurva flooding yang dibagi menjadi 3 bagian, dimana masing-masing mekanismenya tergantung pada laju aliran cairan. Untuk laju aliran yang rendah, terjadinya flooding diawali hydraulic jump yang terjadi di dekat belokan dan pada laju aliran menengah, flooding diawali hydraulic jump yang terjadi di dekat outlet cairan. Sedangkan untuk laju aliran cairan tinggi terjadinya flooding tidak diawali hydraulic jump.

Valley (2008) mengemukakan bahwa posisi dan ketebalan lapisan dari hydraulic jump dipengaruhi oleh besar laju aliran air dan udara. Pada laju aliran air yang rendah, hydraulic jump sangat tipis dan terjadi dekat dengan belokan. Pada laju aliran air yang tinggi, hydraulic jump semakin tebal dan terjadi jauh dari belokan. Pada laju aliran air yang sangat tinggi, hydraulic jump tidak terjadi. Ketebalan film pada hydraulic jump terlihat pada Gambar 3.

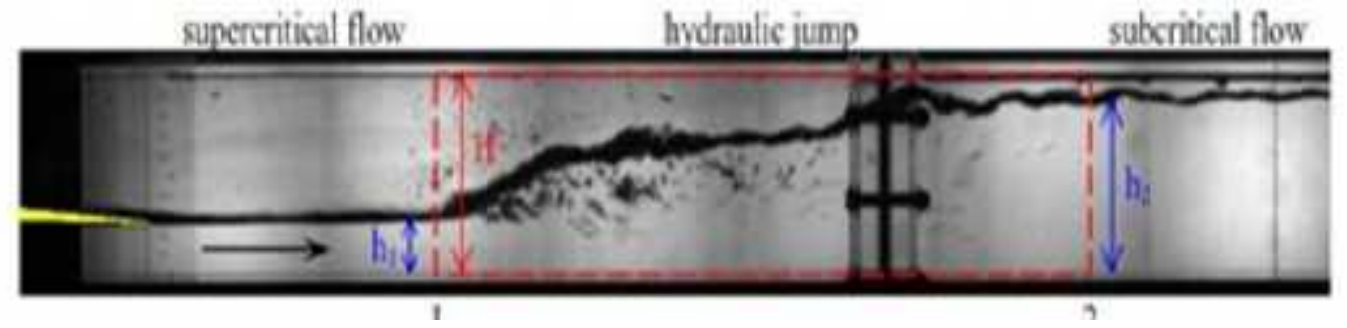

Gambar 3. Fenomena hydraulic jump (Valley 2010)

Dalam aliran dua fase berlawanan arah, parameter kecepatan superfisial merupakan perbandingan laju aliran volumetrik terhadap total luasan dari aliran. Sehingga kecepatan superfisial air didapatkan Rumus (1):

$$
I_{L}=\frac{Q_{L}}{A}
$$

Keterangan:

$\mathrm{J}_{\mathrm{L}} \quad=$ Kecepatan superfisial liquid $(\mathrm{m} / \mathrm{s})$

A $\quad=$ Total luasan aliran

$\mathrm{Q}_{\mathrm{L}} \quad=$ Debit aliran liquid

Aliran superkritis terjadi apabila nilai

Fr $>1$. Pada aliran superkritis, gaya inersia lebih mendominasi dibandingkan dengan gaya gravitasi. Aliran ini ditandai dengan penurunan ketebalan film seiring meningkatnya kecepatan aliran.

Aliran subkritis terjadi apabila nilai $\mathrm{Fr}<1$. Pada aliran subkritis, gaya gravitasi lebih mendominasi dibandingkan dengan gaya inersia. Aliran ini ditandai dengan peningkatan ketebalan lapisan air seiring menurunnya kecepatan aliran.

Aliran kritis terjadi apabila nilai $\mathrm{Fr}=$ 1. Pada aliran kritis gaya inersia sama dengan gaya gravitasi. Aliran ini ditandai dengan adanya fenomena hydraulic jump.

Besarnya tebal film baik pada kondisi superkitis maupun subkritis diperoleh dari video yang diubah menjadi potongan gambar 
secara berurutan. Selanjutnya gambar diolah untuk dilakukan analisa dengan menggunakan sebuah program. Penentuan tebal film pada superkitis maupun subkritis dengan cara mengambil titik sebelum dan sesudah terbentuknya hydraulic jump. Penentuan tebal film ditarik garis lurus selanjutnya garis dipindahkan pada meteran diatas hot leg.

Tujuan penelitian ini adalah mengidentifikasi secara visual posisi dan karakter hydraulic jump pada seksi uji. Data yang didapat dari penelitian dapat digunakan sebagai database pendukung penelitian selanjutnya.

\section{METODE PENELITIAN}

Pada penelitian ini bertujuan untuk mendapatkan data yang berhubungan dengan hydraulic jump pada pipa horizontal dengan beberapa variasi debit air, yaitu $\mathrm{QL}=1,2 \mathrm{lpm}$ $(\mathrm{JL}=0.039 \mathrm{~m} / \mathrm{s}) ; \mathrm{QL}=2,4 \mathrm{lpm}(\mathrm{JL}=0.079$ $\mathrm{m} / \mathrm{s}) ; \mathrm{QL}=3 \mathrm{lpm}(\mathrm{JL}=0.099 \mathrm{~m} / \mathrm{s})$. Pada debit yang kecil diwakili pada $\mathrm{QL}=1,2 \mathrm{lpm}$ karena tebal film lebih tipis dan hydraulic jump berlangsung hingga debit udara yang besar, debit yang sedang diwakili $\mathrm{QL}=2,4$ lpm dengan tebal film yang lebih tebal dan pada debit yang besar diwakili $\mathrm{QL}=3 \mathrm{lpm}$ dengan tebal film yang tebal dan hydraulic jump berlangsung hanya pada debit udara yang kecil. Penelitian dilakukan menggunakan kamera berkecepatan tinggi, sehingga didapatkan hasil secara visual lebih detail dan lebih teliti. Pengambilan data dilakukan pada kondisi steady state dan adiabatis. Udara dan air dimodelkan sebagai aliran gas dan cair yang diuji pada kondisi atmosfer. Perangkat uji, meliputi sistem pemipaan dan kamera video kecepatan tinggi.

Pada penelitian ini simulator hot leg dibuat dengan perbandingan panjang (L) dan diameter saluran (D) sebesar 50 dengan diameternya $25,4 \mathrm{~mm}$. Simulator ini terdiri dari pipa horizontal, belokan dan miring dengan sudut kemiringan $50^{\circ}$. Air dialirkan pada hot leg dari kanan ke kiri dengan debit yang konstan. Selanjutnya dalam waktu yang bersamaan udara dialirkan dari kiri ke kanan dengan kenaikan debit secara periodik sebesar $5 \mathrm{lpm}$ setiap 15 detik. Sehingga pada daerah simulator hot leg akan terjadi aliran berlawanan arah antara udara dan air. Pengambilan data secara visual dilakukan pada daerah simulator hot leg sehingga hydraulic jump dapat diamati. Skema hot leg akan terlihat pada Gambar 4.

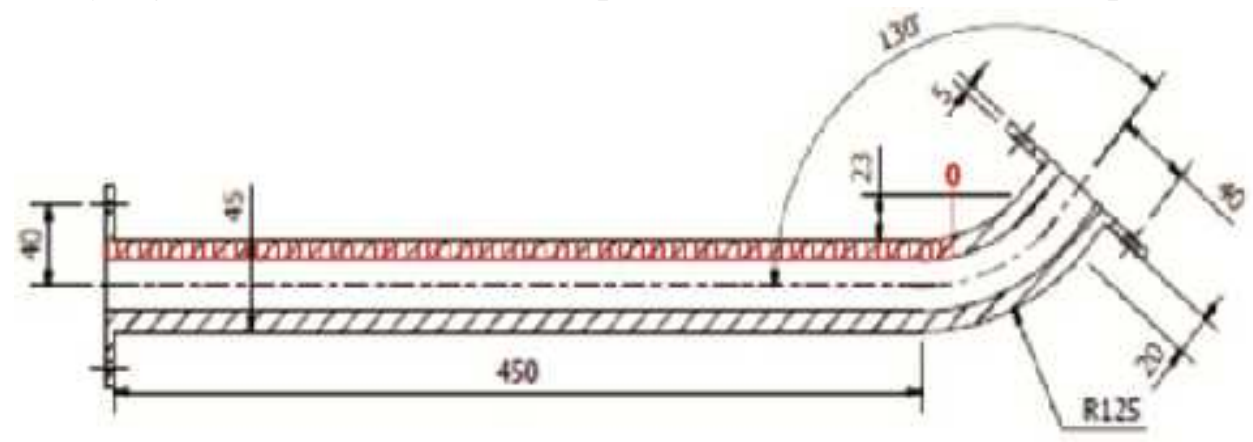

Gambar 4. Simulator hot leg

\section{HASIL DAN PEMBAHASAN}


Penelitian mengenai karakteristik aliran berlawanan arah udara - air pada pipa kompleks telah dilakukan pada variasi panjang pipa dan kecepatan air maupun udara sesuai dengan rencana. Perbandingan panjang pipa dengan diameter pipa disebut dengan L/D. Diameter dalam pipa yang digunakan dalam penelitian ini yaitu 25,4 $\mathrm{mm}$, namun panjang pipa bervariasi $635 \mathrm{~mm}$ dan $1270 \mathrm{~mm}$. Penelitian ini dapat dikatakan dengan variasi $\mathrm{L} / \mathrm{D}=25$ dan $\mathrm{L} / \mathrm{D}=50$.

Fenomena yang terjadi pada aliran penelitian ini dibagi menjadi 3 daerah dengan ciri masing-masing terutama pada tebal film dan posisi hydraulic jump. Daerah pertama pada kecepatan air $\mathrm{J}_{\mathrm{L}}=0,003 \mathrm{~m} / \mathrm{s}\left(\mathrm{Q}_{\mathrm{L}}=0,1\right.$ $1 \mathrm{pm})-\mathrm{J}_{\mathrm{L}}=0,06 \mathrm{~m} / \mathrm{s}(1,8 \mathrm{lpm})$ diwakili pada data $\mathrm{J}_{\mathrm{L}}=0,04 \mathrm{~m} / \mathrm{s}\left(\mathrm{Q}_{\mathrm{L}}=1,2 \mathrm{lpm}\right)$. Pada daerah ini mekanisme hydraulic jump sangat tipis dan berada pada pipa horizontal dekat dari elbow serta flooding terjadi pada kecepatan udara besar. Daerah kedua pada kecepatan air $\mathrm{J}_{\mathrm{L}}=0,06 \mathrm{~m} / \mathrm{s}\left(\mathrm{Q}_{\mathrm{L}}=1,9 \mathrm{lpm}\right)-$ $\mathrm{J}_{\mathrm{L}}=0,09 \mathrm{~m} / \mathrm{s}(2,6 \mathrm{lpm})$ diwakili data pada $\mathrm{J}_{\mathrm{L}}=0,08 \mathrm{~m} / \mathrm{s}\left(\mathrm{Q}_{\mathrm{L}}=2,4 \mathrm{lpm}\right)$. Pada daerah ini mekanisme hydraulic jump berada lebih jauh dari elbow dan flooding terjadi pada kecepatan udara yang sedang. Daerah ketiga pada kecepatan air $\mathrm{J}_{\mathrm{L}}=0,09 \mathrm{~m} / \mathrm{s} \quad\left(\mathrm{Q}_{\mathrm{L}}=2,7\right.$ $\mathrm{lpm})-\mathrm{J}_{\mathrm{L}}=0,11 \mathrm{~m} / \mathrm{s}\left(\mathrm{Q}_{\mathrm{L}}=3,2 \mathrm{lpm}\right)$ diwakili data penelitian pada $\mathrm{J}_{\mathrm{L}}=0,10 \mathrm{~m} / \mathrm{s}\left(\mathrm{Q}_{\mathrm{L}}=3\right.$ lpm). Pada daerah ini mekanisme hydraulic jump berada jauh elbow dan flooding terjadi pada kecepatan udara yang kecil.

Kamera berkecepatan tinggi digunakan dalam penelitian ini sebagai media perekam data sehingga hasil yang didapat lebih jelas dan lebih teliti. Hasil video yang diperoleh digunakan untuk mempelajari perilaku aliran berlawanan arah sebagai data penelitian. Perubahan pola aliran terjadi dengan seiring peningkatan kecepatan udara. Beberapa fenomena dapat dilihat pada setiap panjang pipa seperti fenomena aliran, interface, hydraulic jump, flooding dan gelombang balik dengan variasi aliran air maupun udara.

\section{Fenomena aliran pada $L / D=25$}

Fenomena aliran disebabkan dengan peningkatan kecepatan air dan udara. Pengamatan aliran terjadi pada kecepatan air yang konstan dengan peningkatan kecepatan udara. Fenomena aliran ini dapat ditunjukkan Gambar 5. :

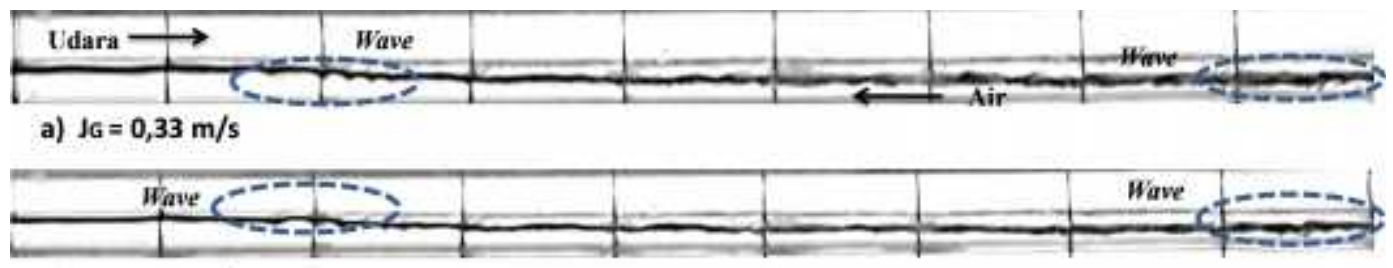

b) $J G=0,99 \mathrm{~m} / \mathrm{s}$

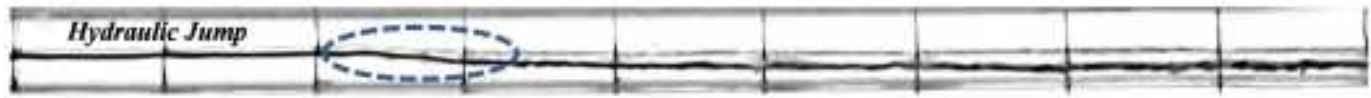

c) $J G=1,64 \mathrm{~m} / \mathrm{s}$

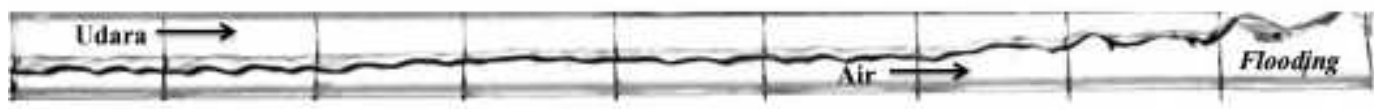

d) JG $=2,30 \mathrm{~m} / \mathrm{s}$

Gambar 5. Aliran pada JL =0,04 m/s 
Aliran yang ditunjukkan Gambar 5.a) pola aliran yang terjadi berupa stratified wavy di mana wave sangat kecil atau biasa disebut ripple. Hal ini terjadi karena kecepatan udara kecil sehingga pengaruh gangguan antarmuka air dan udara kecil. Peningkatan kecepatan udara pada $\mathrm{J}_{\mathrm{G}}=0,99$ $\mathrm{m} / \mathrm{s}$ gangguan antarmuka air semakin besar menyebabkan wave semakin terlihat jelas pada bagian dekat dengan elbow ditunjukkan Gambar 5.b). Semakin besar kecepatan udara pada $\mathrm{J}_{\mathrm{G}}=1,64 \mathrm{~m} / \mathrm{s}$, air akan terdorong dan menimbulkan hydraulic jump seperti Gambar 5.c). Hydraulic jump terjadi karena pengaruh dorongan udara dari kiri dan dorongan air dari kanan. Peningkatan kecepatan udara yang besar pada $\mathrm{J}_{\mathrm{G}}=2,30$ $\mathrm{m} / \mathrm{s}$ menyebabkan perubahan arah aliran air menjadi searah dengan aliran udara dan bergerak menuju elbow. Peristiwa ini disebut dengan flooding ditunjukkan Gambar 5.d).

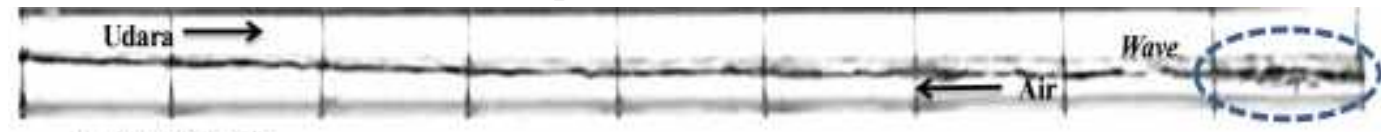

a) $J_{G}=0,33 \mathrm{~m} / \mathrm{s}$

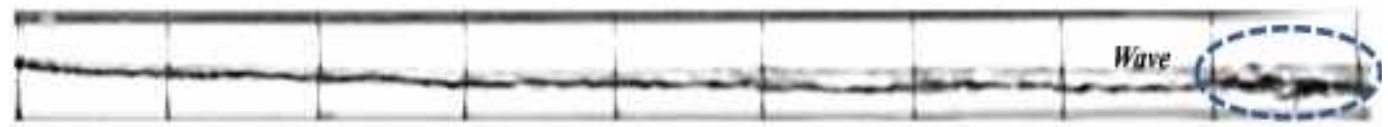

b) $\mathrm{JG}_{\mathrm{G}}=0,99 \mathrm{~m} / \mathrm{s}$

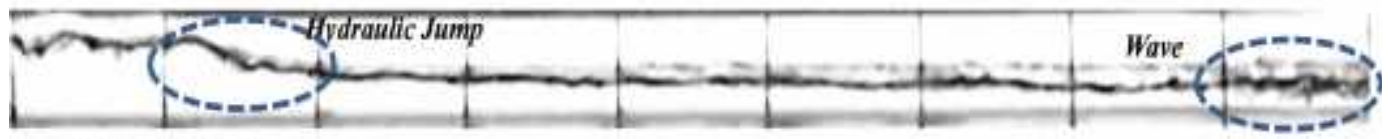

c) JG $=1,48 \mathrm{~m} / \mathrm{s}$

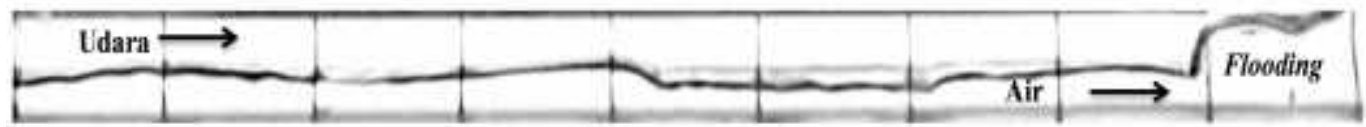

d) $\mathrm{JG}=1,64 \mathrm{~m} / \mathrm{s}$

Gambar 6. Aliran pada $\mathrm{J}_{\mathrm{L}}=0,08 \mathrm{~m} / \mathrm{s}$

Stratified wavy dengan ripple terlihat jelas dan berada pada bagian dekat elbow ditunjukkan Gambar 6.a). Hal ini terjadi karena perubahan kecepatan pengaruh dari perubahan geometri pipa dari miring menjadi horizontal. Peningkatan kecepatan udara pada $\mathrm{J}_{\mathrm{G}}=0,99 \mathrm{~m} / \mathrm{s}$, dorongan udara terhadap air dari kiri semakin besar sehingga tebal film pada bagian kiri semakin tebal ditunjukkan Gambar 6.b). Semakin besar kecepatan udara pada $\mathrm{J}_{\mathrm{G}}=1,48 \mathrm{~m} / \mathrm{s}$ dorongan udara terhadap air semakin besar menyebabkan timbulnya hydraulic jump dan gangguan antar muka yang cukup besar pada bagian kiri menyebabkan wave ditunjukkan Gambar 6.c). Peningkatan kecepatan udara yang besar pada $\mathrm{J}_{\mathrm{G}}=1,64 \mathrm{~m} / \mathrm{s}$, dorongan udara semakin kuat menyebabkan perubahan arah aliran air menjadi searah dengan aliran udara menuju elbow atau biasa disebut dengan flooding ditunjukkan Gambar 6.d). 


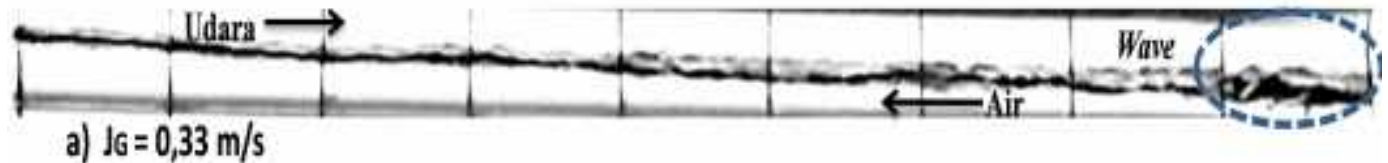

a) JG $=0,33 \mathrm{~m} / \mathrm{s}$
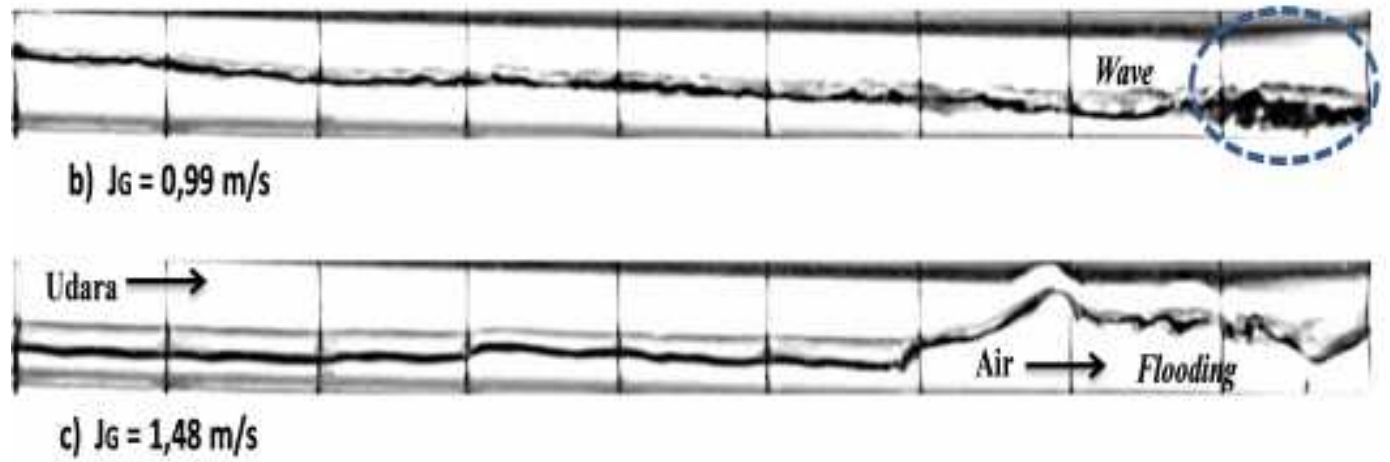

Gambar 7. Aliran pada $\mathrm{J}_{\mathrm{L}}=0,10 \mathrm{~m} / \mathrm{s}$

Pada Gambar 7.a) menunjukkan stratified wavy di mana wave terlihat jelas dan tajam pada bagian kanan. Kecepatan air yang besar dan sedikit aliran udara, gangguan antarmuka semakin besar. Peningkatan kecepatan udara pada $\mathrm{J}_{\mathrm{G}}=0,99 \mathrm{~m} / \mathrm{s}$, gangguan antarmuka air akan semakin besar sehingga wave akan muncul di bagian kanan ditunjukkan Gambar 7.b). Hal ini terjadi karena dorongan udara dan air sama - sama kuat. Kecepatan udara pada $\mathrm{J}_{\mathrm{G}}=1,48 \mathrm{~m} / \mathrm{s}$ dorongan udara semakin kuat menyebabkan penipisan lapisan film di kiri dan perubahan arah aliran air menjadi searah dengan aliran udara menuju elbow. Peristiwa ini disebut dengan flooding ditunjukkan Gambar 7.c).

\section{Fenomena aliran pada $L / D=50$}

Diameter 25,4 $\mathrm{mm}$ dan panjang 1270 $\mathrm{mm}$ dapat disebut dengan $\mathrm{L} / \mathrm{D}=50$. Beberapa karakter yang dapat dilihat, antara lain:

Perubahan aliran terjadi karena perubahan kecepatan air maupun kecepatan udara. Perubahan aliran pada pipa panjang ini ditunjukkan Gambar 8.

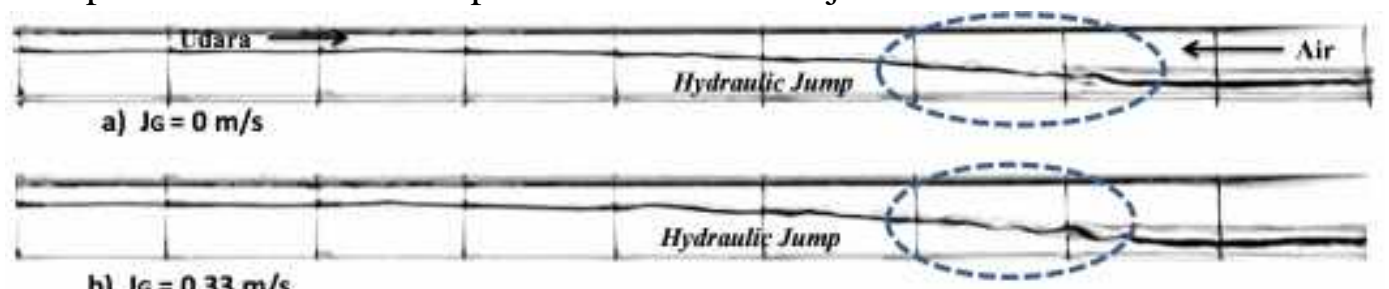

b) $J G=0,33 \mathrm{~m} / \mathrm{s}$

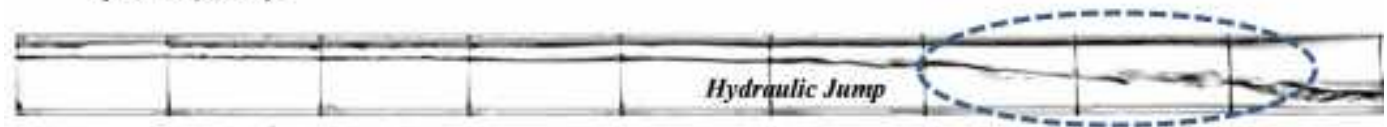

c) $J G=0,99 \mathrm{~m} / \mathrm{s}$

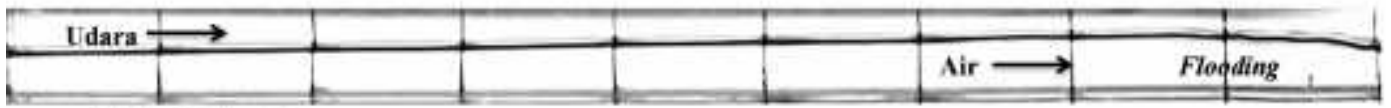

d) $J G=1,64 \mathrm{~m} / \mathrm{s}$

Gambar 8. Aliran pada $\mathrm{J}_{\mathrm{L}}=0,04 \mathrm{~m} / \mathrm{s}$ 
Tanpa aliran udara hydraulic jump terlihat jelas ditunjukkan Gambar 8.a). Dengan peningkatan kecepatan udara Gambar 8.b) pada $\mathrm{J}_{\mathrm{G}}=0,33 \mathrm{~m} / \mathrm{s}$ hydraulic jump masih dalam bentuk yang sama. Peningkatan kecepatan udara menyebabkan air akan terdorong menuju elbow dan lapisan film subkritis semakin meningkat hampir memenuhi pipa ditunjukkan Gambar 8.c).
Peningkatan aliran udara menyebabkan perubahan aliran air menjadi searah dengan aliran udara menuju elbow. Flooding terjadi pada bagian pipa miring, elbow serta upper tank. Pipa horizontal hanya terlihat penebalan film yang sangat tajam ketika terjadi flooding dapat ditunjukkan Gambar 8.d)
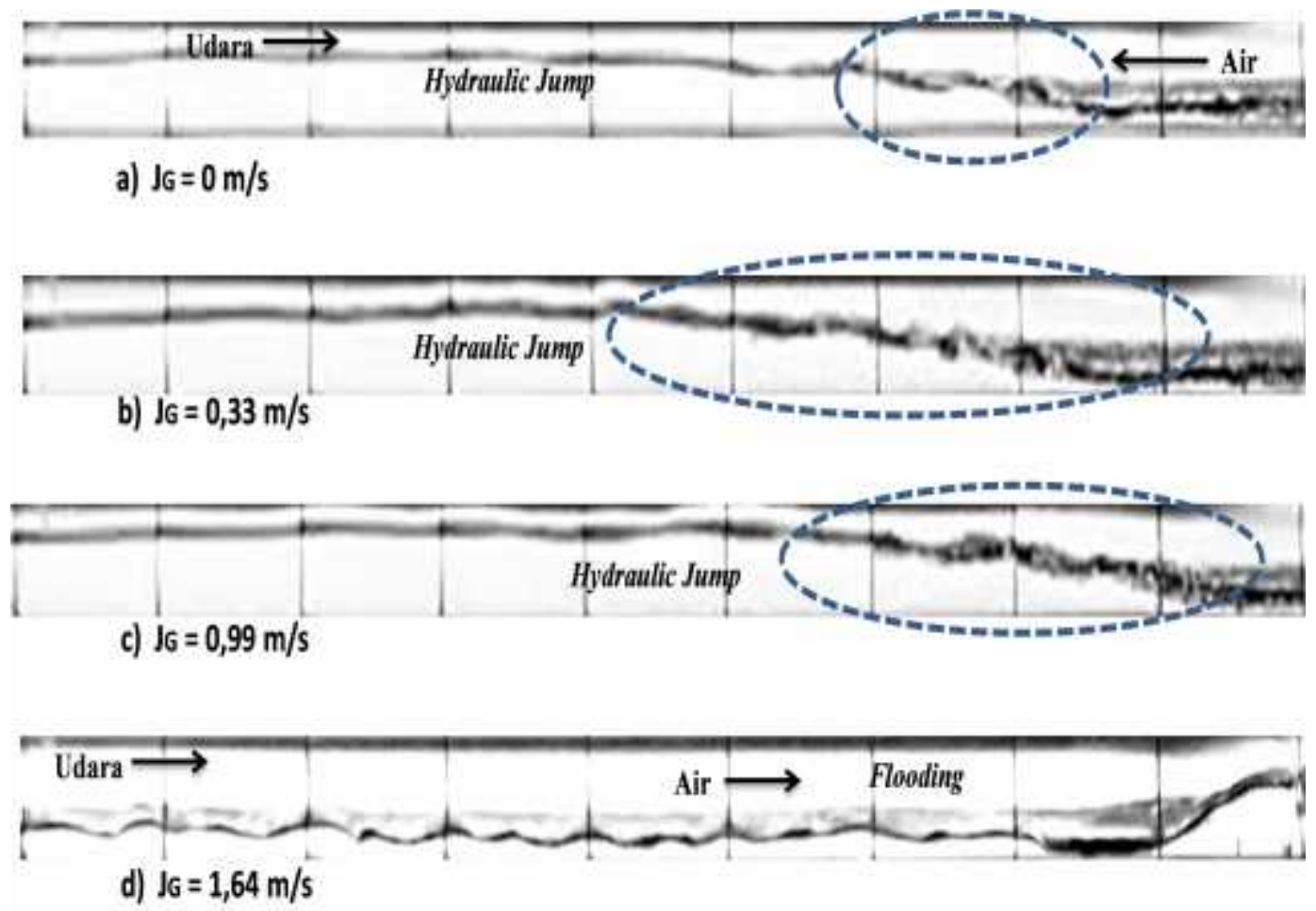

Gambar 9. Aliran pada $\mathrm{J}_{\mathrm{L}}=0,08 \mathrm{~m} / \mathrm{s}$

Tanpa aliran udara hydraulic jump terlihat jelas ditunjukkan Gambar 9.a). Hydraulic jump muncul dan bertambah panjang pada $\mathrm{J}_{\mathrm{G}}=$ $0,33 \mathrm{~m} / \mathrm{s}$ ditunjukkan Gambar 9.b). Peningkatan kecepatan udara menyebabkan air akan terdorong menuju elbow dan lapisan film subkritis semakin meningkat hampir menyentuh dinding pipa terlihat seperti ditunjukkan Gambar 9.c). Peningkatan kecepatan udara yang kecil menyebabkan air terdorong hampir memenuhi ruang dalam pipa selanjutnya terjadi flooding ditunjukkan Gambar 9.d). 

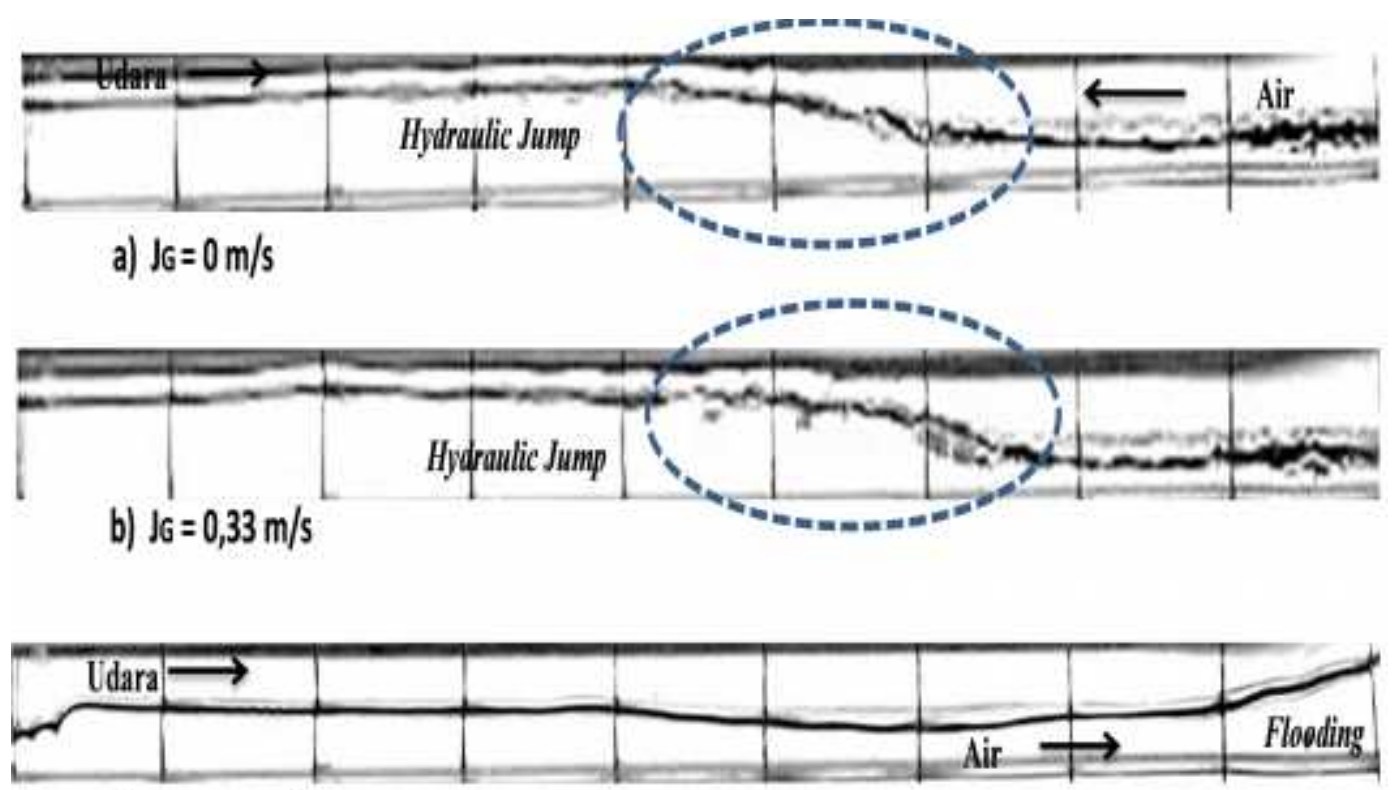

c) $J_{G}=0,99 \mathrm{~m} / \mathrm{s}$

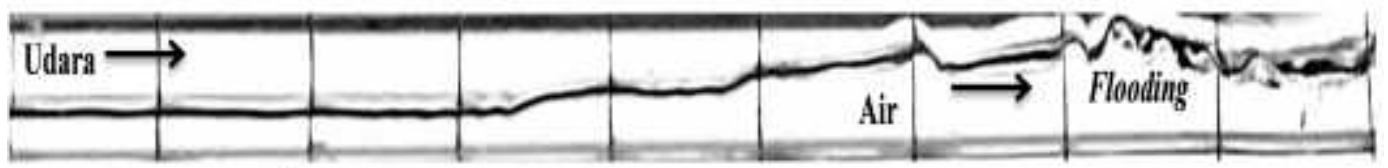

d) $J_{G}=1,64 \mathrm{~m} / \mathrm{s}$

Gambar 10. Aliran pada $\mathrm{J}_{\mathrm{L}}=0,10 \mathrm{~m} / \mathrm{s}$

Tanpa aliran hydraulic jump terlihat jelas ditunjukkan Gambar 10.a). Hydraulic jump dan wave muncul pada subkritis dengan peningkatan kecepatan udara pada $\mathrm{J}_{\mathrm{G}}=0,33$ $\mathrm{m} / \mathrm{s}$ ditunjukkan Gambar 10.b). Hydraulic jump memanjang dan lapisan film subkritis semakin tebal saat peningkatan kecepatan udara ditunjukkan Gambar 10.c). Peningkatan sedikit aliran udara menyebabkan air akan terdorong dan memenuhi pipa selanjutnya menyebabkan flooding ditunjukkan Gambar 10.d).

Hydraulic jump selalu terjadi di awal pada berbagai kecepatan air dalam waktu yang cukup lama selanjutnya flooding.
Mekanisme ini terjadi pada pipa yang panjang, karena gesekan air terhadap dinding pipa besar. Gesekan yang besar menyebabkan lapisan film semakin tebal dan ruang udara semakin sempit. Ruang udara yang sempit menyebabkan perubahan pola aliran air akan berubah memerlukan waktu yang singkat.

\section{Fenomena perbandingan aliran $L / D$} = 25 dan L/D 50

Fenomena pola aliran dapat dilihat perbedaan antara $\mathrm{L} / \mathrm{D}=25$ dan $\mathrm{L} / \mathrm{D}=50$ ditunjukkan Gambar 11. 


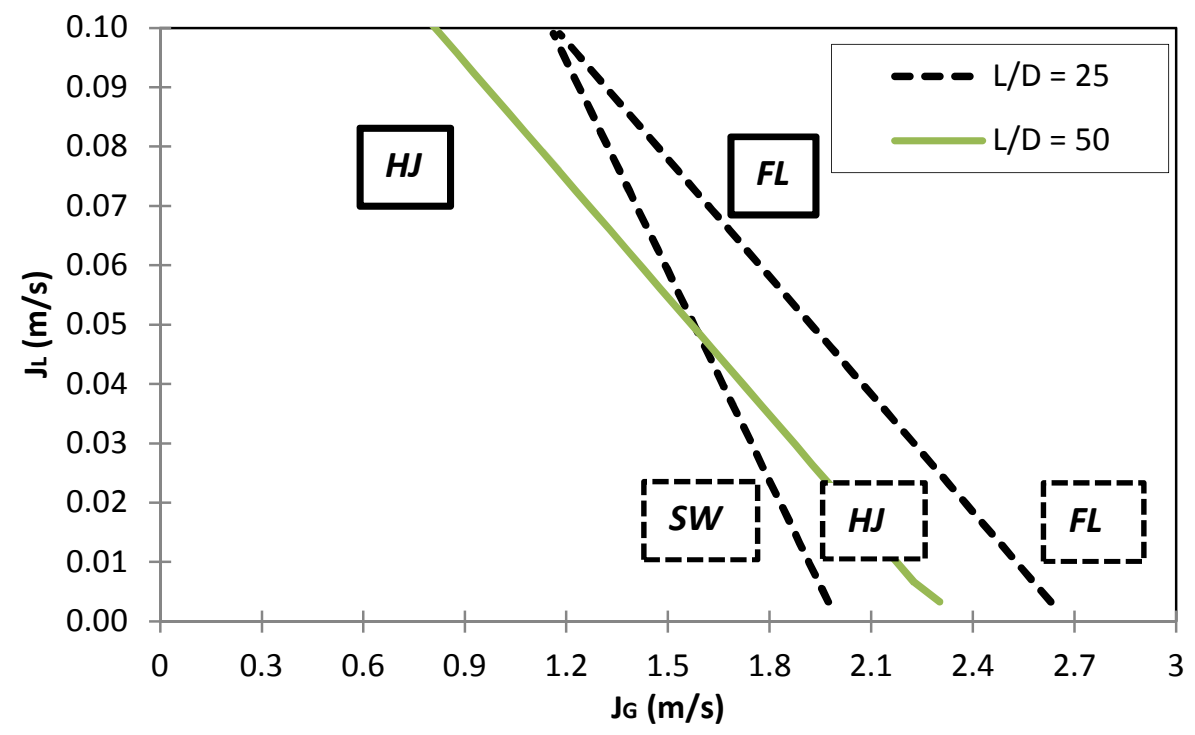

Gambar 11. Peta fenomena aliran L/D $=25$ dan $\mathrm{L} / \mathrm{D}=50$

Peta fenomena aliran dari kedua L/D memiliki sifat yang berbeda antara lain :

1. Pada $L / D=25$ aliran selalu diawali stratified wavy yang cukup lama hingga $\mathrm{JG}=1,64 \mathrm{~m} / \mathrm{s}$. Pada $\mathrm{L} / \mathrm{D}=50$ selalu langsung diawali dengan

2. munculnya hydraulic jump tanpa diawali stratified wavy.

3. Interface pada $\mathrm{L} / \mathrm{D}=50$ akan lebih stabil dibandingkan $\mathrm{L} / \mathrm{D}=25$.

4. Flooding pada $\mathrm{L} / \mathrm{D}=50$ akan lebih cepat terjadi dibanding pada $\mathrm{L} / \mathrm{D}=25$. Flooding pada $\mathrm{L} / \mathrm{D}=25$ terjadi pada $\mathrm{JG}$ $=1,81 \mathrm{~m} / \mathrm{s}$ dan pada $\mathrm{L} / \mathrm{D}=50$ flooding terjadi pada $\mathrm{JG}=0,99 \mathrm{~m} / \mathrm{s}$.

5. Penambahan kecepatan udara menyebabkan cepat terjadinya perubahan pola aliran pada $\mathrm{L} / \mathrm{D}=50$. Sedangkan, pada $\mathrm{L} / \mathrm{D}=25$ perubahan pola aliran dapat terjadi dengan kecepatan udara yang besar.

Bila kecepatan aliran cairan (JL) diperbesar maka untuk mendapatkan perubahan pola aliran diperlukan kecepatan udara (JG) yang lebih kecil. Hal ini berarti ketika kecepatan cairan diperbesar, maka pola flooding semakin mudah terjadi. (Badarudin,dkk.,2014)

\section{SIMPULAN}

Fenomena pola aliran berlawanan arah air dan udara pada pipa hot leg, maka dapat ditarik kesimpulan sebagai berikut:

1. Fenomena aliran akan berbeda pada L/D berbeda.

2. Lapisan film dipengaruhi oleh panjang pipa pada kondisi aliran air dan udara yang konstan. Semakin panjang pipa, maka tebal film akan semakin besar.

3. Interface berupa wave selalu terjadi pada semua panjang pipa dan kecepatan air terlebih di bagian kanan. Hal ini terjadi akibat perubahan geometri pipa dan tumpukan dorongan udara pada bagian kanan.

4. Tanpa aliran udara fenomena hydraulic jump terlihat, hal ini disebabkan karena perubahan geometri pipa aliran dari miring ke horizontal. 
Journal Of Vocational Education And Technology Vol. 01, No. 1, April 2020

5. Seiring peningkatan kecepatan udara (JG) maka posisi hydraulic jump akan bergerak mendekati elbow pada semua variasi kecepatan air.

6. Hydraulic jump terletak pada posisi yang berbeda pada beberapa kecepatan air tanpa aliran udara. Semakin besar kecepatan air, maka posisi hydraulic jump akan mendekati elbow.

7. Tanpa aliran udara gradien ketebalan film meningkat seiring meningkatnya kecepatan air.

\section{UCAPAN TERIMA KASIH}

Terima kasih kepada Prof. Indarto, DEA dan Dr Deendarlianto, M.Eng, Departemen Teknik Mesin dan Industri, UGM, Bapak Dr. Apip Badarudin, M.Eng (Politeknik Negeri Bandung.) Semua penulis merupakan kontributor utama dalam penelitian dan penyusunan karya tulis ilmiah ini.

\section{DAFTAR PUSTAKA}

Badarudin, Indarto, Deendarlianto., 2014.

Observasi karakteristik CCFL pada pipa kompleks, ReTII IX, pp. 371375.

Barnea, Ben Yoseph, Taitel, 1986. Flooding in Incline Pipes-Effect of Entrance Section, The Canadian Journal of Chemical Engineering, Volume 64.

Choi, K. Y., \& No, H. C., 1995, Experimental Studies of Flooding in Nearly Horizontal Pipes. Int.J.Multiphase Flow Vol.21, No.3, pp. 419-436.

Deendarlianto, Ousaka,A., Kariyasaki,A., Fukano, T., 2004. The effect of surface tension on the flow pattern and countercurrent flow limitaion (CCFL) in gas-liquid two phase flow in an inclined pipe.
Gargalo , M. Schulenberg, T., L.Meyer, \& Laurien, E, 2005, Counter current flow limitations during hot leg injection in pressurized air reactors. Nuclear Engineering and Design 235, pp. 785804.

Mouza. A.A, S.V. Paras, A.J. Karabelas, 2003. Incipient Flooding in Incline Tubes of Small Diameter. International Journal of Multiphase Flow 291395 1412.

T. Seidel, C. Valley, D. Lucas, M. Bayer, Deendarlianto. "Two -Phase Flow Experiment in a Model of the Hot Leg of a Pressurized Water Reactor" Wissenschaftlich-Technische Beriche/Forchungszentrum DresenRossendort; FZD-531,2010.

Vallée, C,. Deendarlianto., Lucas, D., Beyer, M., Pietruske, H., Carl, H., 2008. Experimental Study on the Air/water Counter-current Flow Limitation in a Model of the Hot Leg of a Pressurized Water Reactor. Nuclear Engineering and Design, Vol. 238 (12), 3389-3402.

Wongwises, S., $1996 . \quad$ Two-phase countercurrent flow in a model of a pressurized water reactor hot leg, Nuclear Engineering and Design Vol. 166, pp. 121-133. 